\title{
Developing The 7 Stages of Startup (The Maturity Level of Startup): The Concepts of Startup Development Methodology:
}

\author{
Asih Rohmani ${ }^{1}$, Indra Gamayanto ${ }^{2 *}$, Titien S Sükamto ${ }^{3}$ \\ ${ }^{1,2,3}$ Prodi Sistem Informasi Fakultas Ilmu Komputer Universitas Dian Nuswantoro \\ Semarang, Indonesia
}

*Corresponding author: indra.gamayanto@dsn.dinus.ac.id

\begin{abstract}
The development of e-commerce is growing very fast and cannot stop; it changes various sides of human life. This change is a big challenge for everyone, and this is a condition that must occur so that everyone can carry out activities more effectively and efficiently. This research produces a few kinds of Startup classification and Customer Relationship Management (CRM) classification. Furthermore, it provides $C=R . S^{2}$ formula, a formula for developing CRM, and $S=H . I^{2}$.M formula, a formula for developing a Startup. These two formulas were eventually evolving into the seven stages of Startup (the maturity level of Startup), where the seven steps are the stages in developing a Startup, starting from the local level to the international level. These seven stages work so that the Startup founder can gradually understand what needs and how to develop it by focusing more on CRM. The results of this study are a framework to be able to implement the seven stages. This research results from previous studies' development: The Development of Innovative CRM E-Commerce: The Case of Blibli. Com.
\end{abstract}

\section{Keywords : Startup; CRM; The three stages of Startup; Human resource}

\section{Introduction}

Everyone needs to express their mind, but not everyone can do and achieve that. First of all, we need to understand the "nature of the problem," which has a high complexity so that it requires a guide to achieve the things that we want to express. Second, the rapid advancement of information technology changes how we communicate; buy and sell; and create something that affects the entire lifestyle. One way to express what you want is to establish a startup, but this is the first step to change the future. There are still many things that must be understood; understood more deeply; availability of human and capital resources to establish startups.

Furthermore, like CRM, the other side must also consider it because it will make the Startup that has destroyed, survives, and reaches the international level. There are still many challenges in establishing startups, such as lack of availability of highly skilled human resources, how to convince investors, and building infrastructure. This journal's primary focus is on how human resources in a startup can develop to generate profits for startups, excellent service for consumers, and how the Startup can develop into level 3.

This journal is a development of The Development of Innovative CRM E-Commerce: The Case of Blibli.Com. The journal says: "Determining market segmentation strategies is one way to succeed in online business"[1][2]. Moreover, "Online business needs innovation, reliable human resources, and strong infrastructure"[3]. According to Carla S. E. Marques, a high level of sensitivity need to develop a business and take risks. It also requires sufficient capital investment and experience [4]; [5].

Furthermore, the mentoring system must carry out appropriately. The availability of human resources must highly consider. It will result in perfection in customer relations services and information technology infrastructure, which must also strengthen by 


\section{Cisinta}

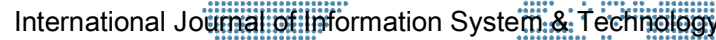
Akreditasi No. 36/E/KP+12019 | Vol. 5, No. 1, 2021$)$ pp:45:50

adopting the latest technology [3];[6]. This journal will produes teir startup and:CRM

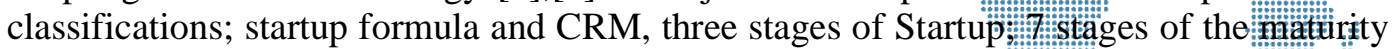
level of startups in developing, and creating a methodology for deexeloping a sustainable startup. This journal will answer why many startups fail and succeed and how a service becomes a determining factor whether the Startup will be able to grow or be chaotic. Therefore, companies must have ways to develop to survive [7]; [8]. Knowing and analyzing economic potential and opportunities in the region [9];[10], and have high motivation in running the company and being innovative [11];[12]. In closing this introduction, startup companies that build must be able to generate new jobs; there is a return of well-calculated capital and increased productivity of human resources capable of facing globalization[13].

\section{Research Methodology}

Figure 1 shows the process of startup development methodology. In the first process, we find some startup problems such as human resources, service, and how to develop a Startup. Furthermore, we used a survey and questioners to collect data. Fifty participants (points 10-100). This survey aims to determine whether consumers are satisfied with online business and whether they need other things that are very important in running an online store to find out what is required by startup companies to develop and reduce future problems. The questions asked are as follows:

Questions 1: Do you often shop online and satisfied?; Questions 2: Is online business serviceable to satisfy customers?; Questions 3: Are the facilities and innovations that online store has been very satisfying customers?; Questions 4: In running an online business, do you need support?; Questions 5: Are connections and guidance so necessary in running a business online?

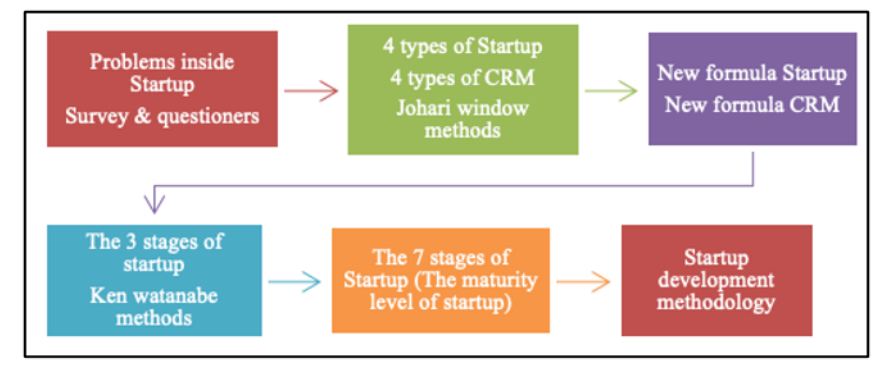

Figure 1. The Process Of Startup Development Methodology

In the second process, we use a Johari window method to classify and types of Startup Company[14], [15]. It can be classified as follows: 4 types of startup-open Startup; blind Startup; hidden Startup; unknown Startup; 4 types of CRM: open CRM; blind CRM; hidden CRM; unknown CRM. The third process, at this stage, produces two Startup and CRM formulas. This formula is an initial innovation to develop startups and CRM to be more systematic. In step four, the founder of the Startup must determine which direction to go, such as: determining the startup model that wants to be built, starting from a simple model, an intermediate model, or an international model (focusing on one) or developing the Startup gradually, starting from the national to global. In stage five, the Startup is acquired further through seven critical steps. The final scene is the implementation of startup development methodology so that startups can develop into a more developed and sustainable company in the face of globalization. It should note that the company's performance must continuously monitor, and the mentoring process must implement adequately to improve the capabilities of startup companies [13];[16]. Therefore, the impact that has been generated by startup companies must be able to make a positive contribution to society [17];[18]. 


\section{Result And Discussion}
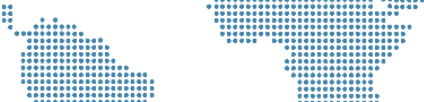

Before you begin to format your paper, first write and save the ee ntent as a text file. Keep your text and graphic files separate until after the itext has been fơmatted and styled. Do not use hard tabs, and limit use of hard returns to onl one return at the end of a paragraph. Do not add any kind of pagination anywhere in the paper. Do not number text heads-the template will do that for you.

The survey results are presented as comparative data so that more accurate and significant results can see; we need to know the results of this survey conducted on 50 participants. Several previous studies have strengthened this survey. According to Yeng Keat, Ooi \& Shuhymee Ahmad, 2012, said: It is necessary to develop entrepreneurial values at the educational level so that they will be able to improve people's lives [19]. Furthermore, in research conducted by Ing. Richard Bednár, Ph.D. \& Ing. Natália Tarišková, Ph.D., 2018, said: "the relationship between startup founders and investors is an essential thing to note" [20]. Because, as Rainer Harms \& Mario Schwery (2020) has said, "entrepreneurs must be more stringent in gathering and managing information when they want to set up their business" [21]. Robert Chou (2020) said, "patent issues are also an important issue that must be highly considered by startups" [22].

These things become the basis in making survey questions that we do in this study so that after the survey. These results can explain as follows:

Questions 1: Results-survey- 10: never 10\%, 20-40: several times 12\%, 50: do not want to answer/hesitate 2\%,60: disappointed with an online business, having no good experience and prefer not to shop again via online 6\%, 70: quite satisfied, but the security in the transaction is still doubtful 14\%, 80: satisfied with an online business $8 \%, 90-100$ often shop through online and satisfied with the services $48 \%$

Questions 2: Results-survey: 10: disappointing 14\%, 20-40: have some problems, the seller does not master the product and cannot explain if the consumer asked 20\%, 50: will not answer 4\%, 60-70: good enough, but still unsatisfactory in explaining to customers $22 \%, 80-100$ very satisfying $40 \%$

Questions 3: Results - survey: 10 disappointing 14\%, 20-40 have some problems, the seller does not master the product and cannot explain if the customers askes $16 \%$, 50: will not answer, 60-70: good enough, but still satisfactory in explaining to customers $28 \%, 80$ 100 very satisfying $42 \%$

Questions 4: Results-survey: 10 no need 12\%, 20-30: 12\%, 40 sometimes need 2\%, 50: will not answer $2 \%, 60-70$ : only trust the people who are known 6\%, 80: need support, but only inside people such as friend 6\%, 90: requires from government and external parties $8 \%, 100$ : need funding and stable cooperation from external and internal parties $52 \%$

Questions 5: Results-survey: 10 not significant 12\%, 20: it is quite, but just want to be guide by known and family 12\%, 30: significant enough requires external guidance $4 \%$, 40: it is quite essential and requires connections and guidance but has limits 2\%, 60-70: simply need a connections in developing an online business, requires guidance only on how to create a website 6\%, 80: need funding to support in developing online business and advice from people who are experts in the field of online business 12\%, 90-100: required cooperation from external parties and investors $52 \%$

The survey results explained that startups still need further development because some questions have not reached more than $50 \%$. Therefore, the framework and formulas that we have designed have several essential steps to overcome the problems that need to solve in the development startup from start to finish. The structure and equations can describe as follows:

\subsection{Stage 1 : Defines Four Types of Startup And CRM}

According to Merriam-Webster, Startup means "the act or an instance of setting in operation or motion" or "a fledgling business enterprise." The American Heritage 


\section{Cisinta}

Dictionary suggests it is "a business or undertaking that has teceently begun operetetton." Therein lies the rub - to be a startup, you must have set up shôp enecently. We wivistifirst redefine Startup in 4 different categories, including open Startup Startup, and unknown Startup. (a) Open Startup: is a type of Startup that can generate and has the innovation that can meet human needs so that this Startup can grow to reach the international level. Furthermore, the resources owned by startups of this type are very supportive, ranging from human resources and infrastructure to sufficient capital. In this section, the segmentation strategy must be applied very well. The strength of this type of Startup is human-capital-infrastructure innovation. This type is called techno-startup; (b) Blind Startup: is a type of Startup that can survive in the current of globalization, but this type only survives but not to reproduce. The existing business model maintains existing ones and develops innovations to survive in the competition[23]. The strength of this type is human-infrastructure resources. This type does not promote innovation too much; change only finishes if needed[24]. This type is called season startup; (c) Hidden Startup: is a closed startup model, meaning that the business model they are doing may look traditional but can still develop further. The strengths of this type are control of the startup owner and the capital he has. This type does not consider human and system resources, but the profit obtained [25]. This type calls learn Startup; (d) Unknown Startup: a startup that does not have a clear vision. Someone starts a business hoping that this company will develop if there are people interested and expect excessive investors' assistance. Still, the business done is not proportional to the capital provided, so there is chaos. The most dangerous thing about this type is deceiving investors, only get money after that; they will close the Startup for various reasons [26]. It is called the deceive startup.

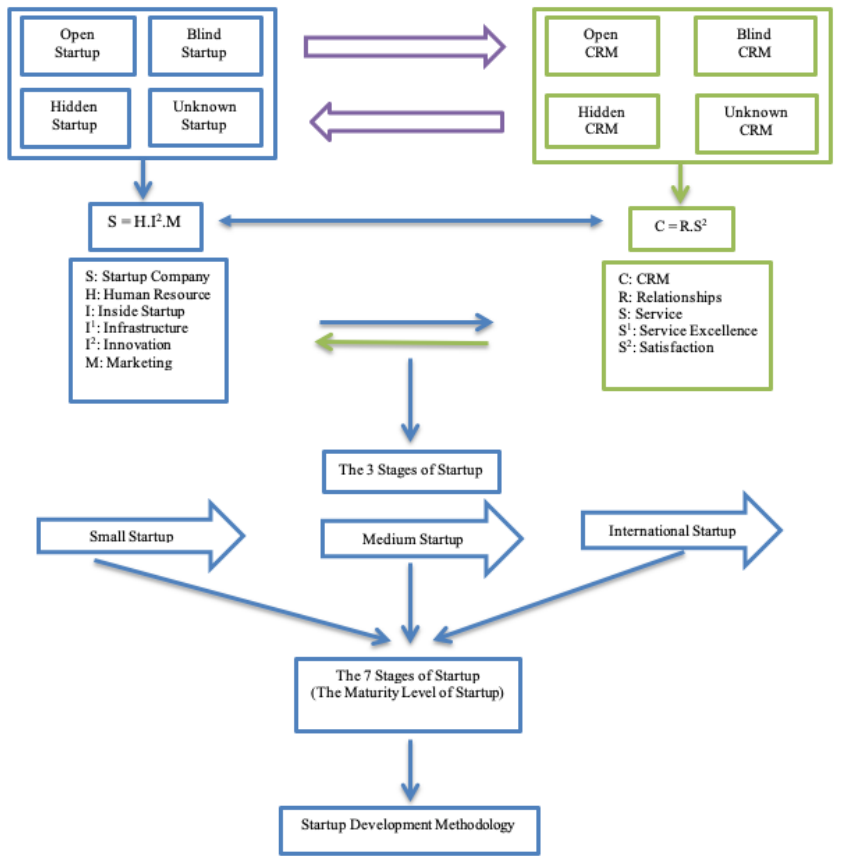

Figure 2. Framework: The Process Of Startup Development Methodology

CRM is a technology for managing all your company's relationships and interactions with customers and potential customers. The goal is simple: Improve business relationships. A CRM system helps companies stay connected to customers, streamline processes, and improve profitability.

(a) Open CRM: is a form of CRM with the highest level of empathy relationship, where consumers feel satisfaction because of the ability of human resources to provide maximum service to consumers, starting from the explanation of products/services; overcome the problem of dissatisfaction and solutions for consumers. Open CRM is one 
of the best types, where the people in it have general knowledge and specific knowtedge. This type also has an excellent customer relationship service infrastructure and êan make the process effective and efficient[27];[28]; (b) Blind CRM: is good enough in building relationships with customers. This typẹcican develop into open CRM but requires more effective human resource management: 'It also opens up to developing innovations so that the technology used can be up-to-date. (c) Hidden CRM is a form of CRM that requires consistent guidance. There are still many shortcomings in this type[29]. We start with the development of human resources, innovation, and technology. Before we understand, we must know that this can achieve if led by someone who can put human resources in the right position and have high creativity. (d) Unknown CRM: is a type of CRM that must develop, where this type has the principle that there is no need to change the old business model that inherits. This type retains what already exists and does not adopt sophisticated information technology. Human resources carry out the same activities from the past to the present, innovation does not exist, and the technique is still very ancient. In this one stage, defining four types of Startup and four types of CRM can describe as follows:

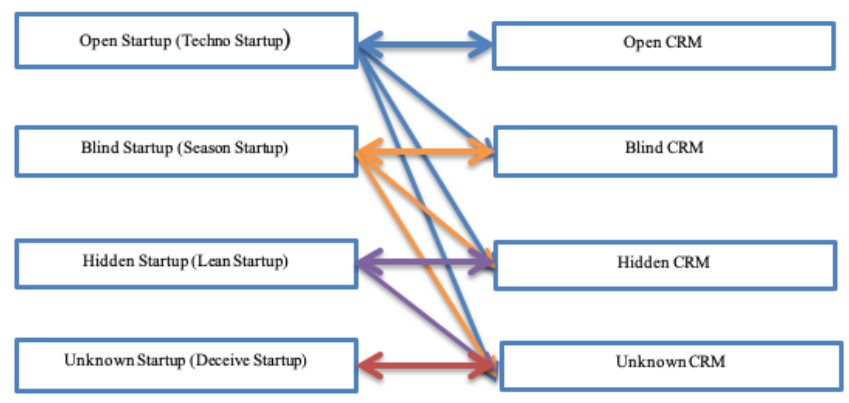

Figure 3. Startup and CRM

The picture above explains that open Startup has perfect open CRM. Furthermore, an open startup can mentor several startup companies that still do not have excellent service. Keep in mind the effort (time and proper guidance) needed to develop the right CRM varies. On blind CRM, it takes 50\%; hidden CRM takes 60\%, and unknown CRM takes $80 \%$. A blind startup has blind CRM that still needs further development. A blind startup can help hidden startups develop CRM; the effort required is $60 \%$, and unknown CRM needs $85 \%$. The hidden Startup has a hidden CRM and can also help unknown CRM in developing its services; the effort required is $90 \%$. In the final part, namely unknown Startup, this type needs to open itself to innovations. This explanation can be summarized as follows:

(a) Open Startup and CRM have ideas and innovations and the availability of highly skilled human resources. Infrastructure and capital are enough to penetrate the market to continue to grow and impact the community. In this section, the service provided is very good to customers [30]; (b) Blind Startup and CRM: need guidance and improve innovation to grow bigger. Sometimes, companies can only survive two to five years, then close because they cannot compete. (c) Hidden Startup and CRM require a CEO and someone who can make radical changes to develop human resources, technology, and development capital. (d) Unknown Startup and CRM: can say to be a business that has been down and down since the first, second, and third generations. The problem is that it still has a long working pattern in producing products. Maintaining the old model is okay, provided the quality of the product guaranteed.

Investors need to be careful when cooperating with the unknown Startup because this will result in no small financial losses. The pattern used is "it seems that it has a very extraordinary vision, but has a Dark motive in it," this fraud often occurs to investors who only have money but do not care about the long term, but the acquisition of profits in the short time. From this explanation, two formulas produce for Startup and CRM. 


\subsection{Stage 2 : Formula Startup And CRM}

Formula startup: $\mathbf{S}=\mathbf{H} . \mathbf{I}^{2}$.M; S: Startup Company; H: Htwman Resource; Startup; I1: Infrastructure; I2: Innovation; M: Marketing; S: is a 数鹤 of startup conpany; $\mathrm{H}$ : human resources contained in startup companies - existing of és and needed human resources; I is a business process included in a startup company; II: ' infrastructure held in startup companies, such as hardware and software; I2: any innovations and ideas contained in startup companies; the concept already exists and thoughts/innovations that will develop; M: startup companies do marketing.

Formula CRM: C = R.S ${ }^{2}$; C: CRM; R: Relationships; S: Service; S1: Service Excellence; S2: Satisfaction; C: is a type of CRM owned by a company. In theory, we need to know that CRM has three kinds, namely Operational, Analytical, and Collaborative. Here, we will not explain the three types of CRM, with assumptions, the readers already know the definition. $\mathrm{C}$ here is a type that has divide into four parts: open; blind; hidden; unknown. R: how companies build good relationships with customers; this is still a lot of problems due to the lack of training in human resources owned by companies to serve consumers effectively. S \& S1 is a service performed by a company to consumers and how the company maintains consumers. S2: is the satisfaction obtained by consumers and companies. These two formulas were further developing into three significant levels in developing a startup company.

\subsection{Stage 3 : The 3 Stages of Startup}
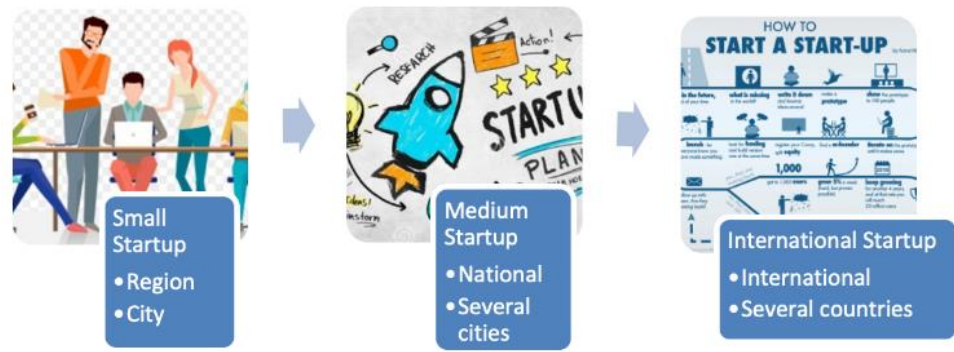

Figure 4. The 3 Stages of Startup

A small startup is a form of a startup that can be said to have two types: small and big enough. Small Startup means that these companies are only established in one area and survive with their market. Companies are usually established by several people who combine business capital to become a company with a lower and middle-level market. This type of Startup focuses on how to return money that spends and benefit from the business[31]. This company does not need complicated and sophisticated training in human resources or has to go through stages of improving capabilities. Because this company has principles: the most important thing is that people know their products/services then become regular customers and how the level of quality becomes the focus, even if the class itself is also essential. This small Startup's strengths centralize model leadership, led by one person to run this business. It has sufficient capital because it establishes several people and a combination of business capital; it does not have a complex system. Increasing the capacity of human resources inside does not become an essential thing. Get profits very quickly because this company already has regular customers. The location does not have to be inside the mall, but can be in one place that is easily accessible by consumers. The products/ services they have are well known to the general public; innovation is not an important issue to be developed within the company.

The disadvantages of this small Startup are centralized leadership is the most significant weak point. If the successor of the business is unable to maintain it, the company will go bankrupt, lack of innovation, human resource management that is very lacking, having a straightforward business system and process, the occurrence of divisions 


\section{asinta}

International Joürmat:of

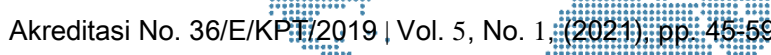

between owners of business capital, the location could be a problemit. it establišleses in an inappropriate place, the products/services offered will tend to teceline if theire no innovation and communication

Big enough Startup is a further development of small Statutup, where the startup company has developed into several business branches in the city. This development occurs because of the additional capital obtained from the company's profits. This development needs innovation. Then, the defense of this company will be tough. Food products that have become a trend or culture from the city will be more sustainable. Still, products/services outside the area are likely to be difficult in maintaining the market and its existence.

The medium Startup is a startup company with a range of cities and can be a nationallevel startup. This startup medium has become broader and has an economic impact on the community. The Startup's medium stage is a critical step, which has three essential choices: Startup becomes significant, the Startup will stop, and the Startup will go bankrupt. At this stage, the founder needs substantial funds to develop a startup. Still, it needs to be understood here; having innovation does not guarantee that the company can succeed. An excellent team is required to develop a marketing system, building infrastructure, and security. This startup medium has several strengths including: (1) Having a reliable and high competency team; (2) excellent financial management; (3) segmentation; target market, and the right location; (4) excellent communication within the company and open in accepting objective opinions and judgments; (5) has a very high vision and effort in developing the Startup that he has built; (6) developing human resources within the organization and being able to place people in the right position, not based on anything else but based on competency and character/attitude that can bring startup companies to the next level; (7) information technology infrastructure that is quite sophisticated.

International Startup, this position is the Startup's highest position, where the Startup has developed into an international level company. The characteristics of this type of Startup have a CEO who has high competence. Financial management and human resources are excellent (it should note here that startup companies can increase without the right human resources, but this defense will not extend. This company will be unable to compete with the company others that develop human resources). Stable information technology infrastructure; transparency in communication and openness in new matters; able to create other leaders below it and compete well in the organization; can develop in several countries (international) and control the national level; People can understand the vision.

This development certainly cannot be done alone; there must be a collaboration between investors and startup founders. Therefore, classified three types of startup founders are reliable: (1) future founder; (2) light founders; (3) thinker founders. The future founder is a startup founder who has systematic long-term thinking. When the execution occurs, this finish in stages, and having reliable human resources is critical. Future founders' weakness is that sometimes people in the organization are afraid to reprimand if the founder makes a mistake because of his thoughts and vision. Here, we need to understand that even though a person has a very high view, he cannot separate from his weaknesses. Therefore, criticism and improvement require others. The light founder is a very patient type in building his company, has a perfect long-term vision; the difference with future founders is the future founder is a type of person who wants to get things done and has apparent ambitions.

In contrast, the light founder is a softer type but still has high self-confidence. Human resource management in the company with a bright founder is undoubtedly excellent and can also maintain two-way communication. Some of the weaknesses that light founders have are the introvert nature that they have can tend to make people less able to understand their mindsets and need reliable partners, such as future founders, to keep their 
ambitions and vision on track. Thinker founder is a type of thinker who is very deepentmore careful, and has a very sharp instinct; innovation comes out of his thinking with abiuiliant aloof in creating something. The thinker founder's weakness is extroverted partner so that its ideas can market even further. After, we understand the three types of startup founders that relied on, then the next is to understand the three types of investors that built on, among others: (1) investor goodness; (2) influential investors; (3) innovative investors. Goodness investors are a very generous type of investor in sharing their ideas. They are accommodating for startup founders in developing their designs, giving investors goodness, a business capital, and providing innovative ideas so that startup companies can be even better. The weakness of investor goodness is that sometimes they dominate thoughts, so if it is too aggressive, the founder of the Startup will be overwhelmed in facing this type of investor. Influential investors are the type of investors who have a lot of money, are very helpful in building startup infrastructure; the other side has human resources that can help startup companies grow faster. Investor's powerful weakness is if the person is too dominating, it will cause the founder to only work for that investor, not as a partner but only as an employee. Innovative investors are affluent in ideas; the difference in investor goodness is that innovative investors are more inclined to long-term research, where innovation takes longer because it requires intense research. The disadvantages of innovative investors are the study's length of time; these innovations can sometimes be outdated.

On the three stages of this Startup, there is a concept from Ken Watanabe regarding human resources[32]. This concept divides into several essential parts, including (1) complainer, (2) critics, (3) dreamer, (4) fast reaction, and (5) problem-solvers. If this is related to the three stages of a startup, it can describe as follows:

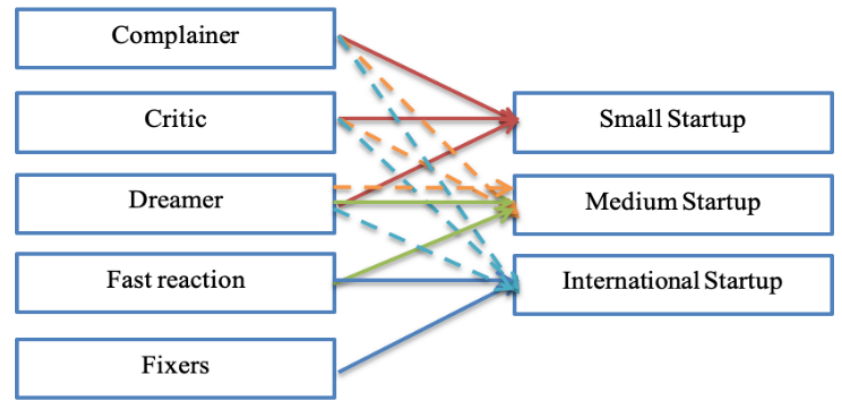

Figure 5. Ken Watanabe Concepts Connected With The Three Stages Of A Startup

The next step is to summarize first the classification of what explains so that it is understood very well. It described and summarized as follows:

In a small startup, there are three types of human resources: (1) complainers; (2) critics; (3) dreamer. It is normal because when you build a startup, people will usually have dreams and big vision in achieving something. If the idea successfully carries out, it will develop into a medium of Startup and even international Startup. In startup companies, there are also complainers and critics. It can also be healthy because building a company is not easy and requires many things to achieve it. Therefore, there will be people who might be said to be exhausted and complaining, some negative thoughts, succeed or not, and criticize what was done by the startup medium founder. There are two types of human resources: (1) dreamers and (2) quick reactions. These two types of human resources have enormous potential in developing human resources, dreams, and visions that execute very fast to become national-level companies that are quite strong and have a broad economic impact on the community. This company cannot separate from the two types that previously existed in the small Startup: complainers and critics, but what is needed more 


\section{Cisinta}

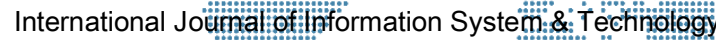

is the critic because this will significantly help the company deciding something and developing the company.

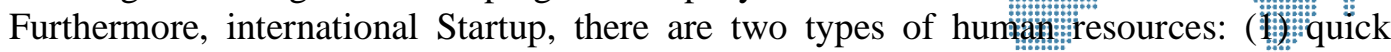
reactions and (2) problem solvers. These two types need to develop startup companies on an international level, where both models can work together, and one person can have both. It certainly requires criticism to grow and know weaknesses and improve the process continuously.

\subsection{Stage 4 : Determine What You Want The Startup Model?}

This stage is a summary in stages 1-4. This stage is an essential thing to understand because it will be able to have an impact on the next stage. First 4 types of startup: (1) open startup (techno startup); (2) blind startup (startup season); (3) hidden startup (learn startup); (4) unknown startup. Of the four types of Startup, which type do you mean? This question takes honestly to know the basic foundation. The four types of CRM: (1) open CRM,(2) CRM blinds; (3) hidden CRM; (4) unknown CRM. It relates to online business, where startups related to e-commerce can say the question posed if you already have an online business, which CRM do you have in which type? Once again, this question answered honestly to determine the foundation for service to consumers, whether already achieved an excellent satisfaction level.

\subsection{Stage 5 : The maturity level of a startup (The seven stages of Startup)}

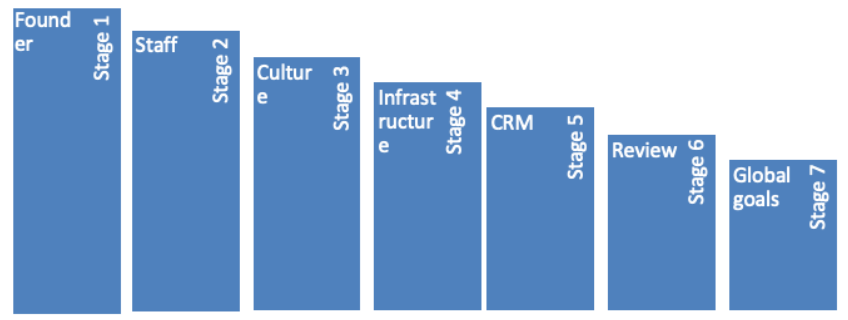

Figure 6. The 7 Stages of Startup (The maturity level of Startup)

These seven stages are essential stages to find out whether the Startup can be said to be able to survive in the face of competition or not. The explanation, a simulation of this implementation, is explained in the next stage. This stage will teach the essential elements in the seven stages of a startup (a startup's maturity level).

According to figure 6, We can see there are 7 stages: stages 1; stages 2; stages 3; stages 4; stages 5; stages 6; stages 7 and 7 elements: founder; staff; culture; infrastructure; CRM; review; global goals.

Stages 1- founder: at this stage, the Startup determines whether they refer to the future category; light or thinker. This stage is critical; if step one cannot be well defined and determined and lay the foundation of certainty, then the Startup will be challenging to get to the next stage.

Stages 2-staff. In this position, startups can use a few simple principles. Human resources are obtained from family principles, meaning families can work together to build a startup business. The law of friendship, that is, our friends who know invited to work together. The principle of good relations is that you have good friends, and good friends have good friends who can be relied upon to work together. The external family principle means that your family has friends. Your friends invite you to work together; foreign policies say you are looking for people outside your circle of friends and family, working together to build a startup business. The internal combination principle, meaning, you combine friends, family, and people outside the circle; the law of external combination says that you only 


\section{asinta}

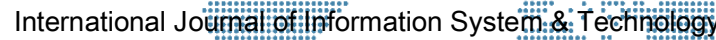

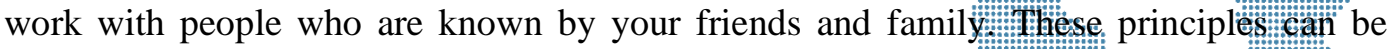
applied flexibly and can reduce the level of risk in building a startupecompany.

Stages 3 -culture: on this stage is a high level of complexity. Founders from startups should not underestimate the strength of a culture. Culture can affect the overall mindset, character, attitude, decisions, and daily habits. The founder, when setting up a startup company, if that is the case, stands in the country and city/region. It will not be a problem, but if the Startup is establishing in another country with a different culture, startups must have alertness. Culture is dividing into three essential parts: (1) culture shock; (2) culture drunk; (3) culture change. Culture shock means that the founder who founded a startup in another country if he does not understand its culture will be surprised by all the people's habits and tastes. Therefore, startups must understand other countries' cultures to avoid the shocking effects of culture, resulting in a startup rejected. Culture drunk means that the founder is confused about facing a country's culture, which causes the startup company to be less reliable in facing the current competition. Culture change means that the founder is very flexible in meeting a country's culture and can handle it very well. In facing different cultures, it might be better to hire local people. Still, with a note, competencies need to be trained very well, this depends on what the startup company sets standards and how to develop human resources. Furthermore, founders of startup companies must form an ethical culture within their own companies, such as communication between line departments to have a process culture. Moreover, the company has standard professionals in standard operating procedures, business processes, and other systems resulting in a level of satisfaction within the company and consumers; the results will build a unique culture.

Stages 4-infrastructure: startup companies must have considerable business capital in building information technology infrastructure on this stage. The types of investors have explained before; startup company owners must choose investors and collaborate with external parties.

Stages 5-CRM: startup companies that established need to understand that the context of services provided to consumers must meet a high level of satisfaction. The power of services such as product/service explanations must be considered, especially regarding consumers' complaints. The thing that can make a startup company go bankrupt is awful service to consumers, where consumers are very disappointed with what is done by the company. Starting from the absence of problem-solving when the goods ordered do not reach consumers, customer service is awful at explaining a process, a very complex website, and no product explanation. Startup companies must be able to do proper management of the seller so that consumers can adequately obtain information about these products.

Stages 6-review: The founder must be able to revise the vision, mission, and objectives of the startup company. It needs two years, one time or three years, one time or five years. It is useful so that startup companies can continue to survive in competitive competition and develop into international companies that significantly influence society and impact improving living standards by opening up more extensive employment opportunities to help the community prosper. We need to understand that vision should aim for continuous profits. Still, images must also have a broader social side and have a positive psychological impact on society. It is the key to the strength of startup companies that will continue to survive. Furthermore, companies must review all business processes that have built to identify problems and resolve them immediately. 


\section{Cisinta}

International Joüunal of Akreditasi No. 36/E/KP特2019 | Vol. 5, No. 1, (2021)

Stages 7- global goals: startup companies must have very high but realistic goấs. Wany startup companies go bankrupt because they do not have realisticic goals and Market segmentation must consider because the right market seginent's determinatuon can bring startup companies to be more significant. This segmentation strategy read in The Development of Innovative CRM E-Commerce: The Case of Blibli:Com.

\subsection{Stage 6 : Startup Development Methodology (HR Methodology)}

Innovative startup $=\mathrm{H} \cdot \mathrm{I}^{2} \cdot \mathrm{M}+\mathrm{C}=\mathrm{R} \cdot \mathrm{S}^{2}+$ The 3 stages of startup + The maturity level of Startup (The 7 stages of startup). This formula is a step in producing innovative startups; this described as follows:

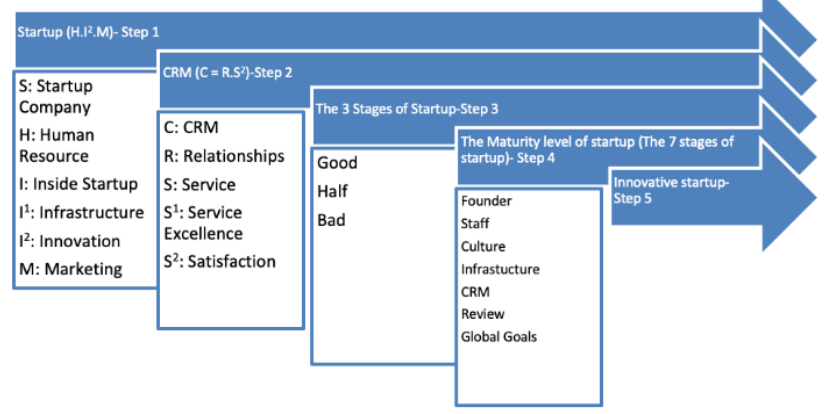

Figure 7. The Step Of Startup Development Methodology

According to figure 7, Step 1: S-startup company. Companies must have human resources that have high competence $(\mathrm{H})$; strong organizational structure and stable communication and building an ethical culture (I); have an information technology infrastructure (I1); innovation that can provide added value to the company and society (I2); marketing power; proper service and market segmentation $(\mathrm{M})$.

Step 2: C: CRM. The company must foster customer relations (R); do excellent service resulting in a high level of satisfaction $(\mathrm{S} ; \mathrm{S} 1 ; \mathrm{S} 2)$

Step 3: The three stages of a startup. Determine the position and classification of the Startup; founder; investor. This stage is a critical stage to be able to build international level startup companies

Step4: The maturity level of a startup (The seven steps of Startup). The founder determines what elements there are weaknesses, so it needs to be corrected. As an example:

Table 1. Example Of The Seven Stages Of A Startup (The Maturity Level)

\begin{tabular}{|l|c|c|c|c|l|l|l|l|}
\hline Stages/element & Stages & Stages & Stages & Stages & Stages & Stages 6 & Stages 7 \\
\hline Founder & BS & $\mathbf{2}$ & $\mathbf{3}$ & $\mathbf{4}$ & $\mathbf{5}$ & & \\
\hline Staff & & & & GS & TB & \\
\hline Culture & & BS & & & & GS; TB & \\
\hline Infrastructure & & BS & & & GS & TB & \\
\hline CRM & & BS & & & GS & & TB \\
\hline Review & BS & & & & GS & & TB \\
\hline Global goals & & & & & & & BS; GS; \\
& & & & & & & TB \\
\hline
\end{tabular}

Case study-1: Bad Startup (BS), Code: Red

The founder of a startup company has very high dreams, but the founder cannot specifically achieve his vision. The founder is in stage 1 position, and even though the startup company is already running, whether it has investors or not, there are serious problems here. The company is tough to develop because it cannot explain what it wants 


\section{Cisinta}

to do to achieve greater success in the future. This startup company only runs itsobusiness with the principle: "have their way and do not want to listen to any opmions." It witum make

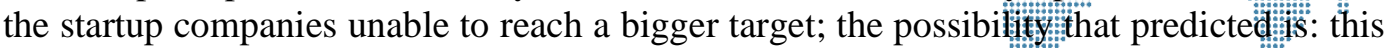
startup company may be able to achieve success in just one areat, but it is difficult to become a national level.

Case study-2: Good Startup (GS), Code: Green

Founders have a vision that can explain and systematic and structured to have the right direction in developing its company. The human resources owned by startup companies are enough to be able to go to the national level. The communication culture that builds is quite good. The information technology infrastructure that has owned is quite good - but still needs development, satisfactory services to consumers, the founder reviews, and always thinks the term long to develop a startup company network.

Case study-3: The Best Startup (TB), Code: Blue

Founders and investors can work very well, where this collaboration can produce a premium startup company. Human resources with very high abilities will consider, and their acceptance will be very strict. Furthermore, infrastructure development and expanding markets not only focus on profits but also what contributions can be given to the community, improve living standards, and provide benefits to the State. According to figure 8 , it is a simplification of the startup development methodology process, where the process divided into three essential parts: step 1- consists of the founder and the three stages of Startup; step 2- investors can work with startup companies with three patterns investors level 1-3; level 1-2 investors; and level 3 investors, meaning investors can cooperate at the level they want; step 3- consists of 2 essential parts - the seven stages of Startup, where to find out the strengths and weaknesses of the startup company so that continuous improvements made to achieve perfection; and eventually, startup companies become companies that can have an impact on companies and society.

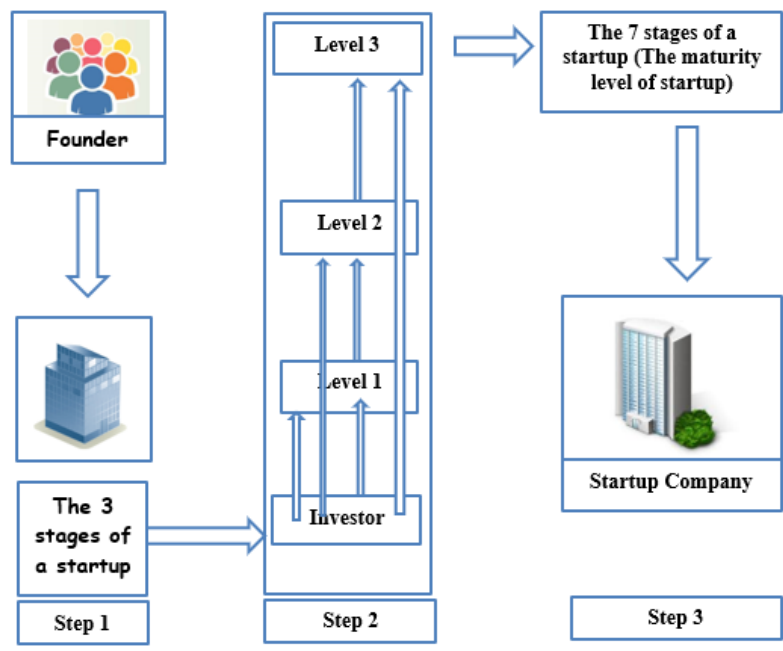

Figure 8. The Three Steps Of Startup Development Methodology (Complete Guide)

\section{Conclusion}

From the results of this study, we can conclude several things, including:

a) The development of startups can occur if you pay attention to several essential things, such as the factors of human resources and services provided. Another critical factor is to have the right investors to assist in the development of the company. 
b) The stages of the startup development methodology franevook These steps should not skip in its application; human resource faetters: are considered a determinant of startups' success. future

c) $\mathrm{S}=\mathrm{H} \cdot \mathrm{I}^{2} . \mathrm{M}$ and $\mathrm{C}=\mathrm{R} . \mathrm{S}^{2}$, are two formulas that can be applied to startups to maintain balance in startup companies so they can survive in global competition

\section{References}

[1] I. Gamayanto, T. S. Sukamto, and Muljono, "Unizon for university in Indonesia: The development of 'university go online' to face ASEAN economic community (AEC)," Proc. - 2017 Int. Semin. Appl. Technol. Inf. Commun. Empower. Technol. a Better Hum. Life, iSemantic 2017, vol. 2018-January, pp. 42-47, 2017, doi: 10.1109/ISEMANTIC.2017.8251841.

[2] I. Gamayanto and H. Christian, "The Development of Innovative CRM ECommerce: The Case of Blibli.Com," Binus Bus. Rev., vol. 9, no. 1, p. 29, 2018, doi: 10.21512/bbr.v9i1.4100.

[3] I. Gamayanto, T. S. Sukamto, and Muljono, "Unizon for university in Indonesia: The development of 'university go online' to face ASEAN economic community (AEC)," Proc. - 2017 Int. Semin. Appl. Technol. Inf. Commun. Empower. Technol. a Better Hum. Life, iSemantic 2017, vol. 2018-Janua, pp. 42-47, 2017, doi: 10.1109/ISEMANTIC.2017.8251841.

[4] M. Caliendo and A. S. Kritikos, "Start-ups by the unemployed: Characteristics, survival and direct employment effects," Small Bus. Econ., vol. 35, no. 1, pp. 7192, 2010, doi: 10.1007/s11187-009-9208-4.

[5] M. Caliendo, J. Hogenacker, S. Künn, and F. Wießner, "Subsidized start-ups out of unemployment: a comparison to regular business start-ups," Small Bus. Econ., vol. 45, no. 1, pp. 165-190, 2015, doi: 10.1007/s11187-015-9646-0.

[6] indra gamayanto, "Pengembangan Mentoring Management Dalam Menghasilkan High Quality Human Resource Di Tingkat Universitas Dalam Menghadapi Masyarakat Ekonomi Asean (Mea) Dengan Menggunakan Konsep Kiyosaki Dan Blanchard Abcd Trust Methods-Hsova," J. Manaj., vol. 13, no. 2, pp. 158-178, 2016, [Online]. Available: https://www.ristekdikti.go.id/strategi-perguruan-tinggi-.

[7] A. Coad, J. S. Frankish, P. Nightingale, and R. G. Roberts, "Business experience and start-up size: Buying more lottery tickets next time around?," Small Bus. Econ., vol. 43, no. 3, pp. 529-547, 2014, doi: 10.1007/s11187-014-9568-2.

[8] J. Munemo, "Business start-up regulations and the complementarity between foreign and domestic investment," Rev. World Econ., vol. 150, no. 4, pp. 745-761, 2014, doi: 10.1007/s10290-014-0189-2.

[9] M. Fritsch and P. Mueller, "The persistence of regional new business formationactivity over time - Assessing the potential of policy promotion programs," $J$. Evol. Econ., vol. 17, no. 3, pp. 299-315, 2007, doi: 10.1007/s00191-007-0056-6.

[10] S. Stathopoulou, "The Location of Markets , Perceived Risk , and Start-up Entrepreneurial Capital of Micro Rural Firms," Small Bus. Econ., vol. 25, no. 2, pp. 147-158, 2012, doi: 10.1007/sl.

[11] M. da Costa Filho, E et al., "The nascent entrepreneurship hub: goals, entrepreneurial self-efficacy and start-up outcomes," Int. J. Morphol., vol. 32, no. 2, pp. 652-655, 2012, doi: 10.1007/s11187-011-9355-2.

[12] D. M. Hechavarría, C. H. Matthews, and P. D. Reynolds, "Does start-up financing influence start-up speed? Evidence from the panel study of entrepreneurial dynamics," Small Bus. Econ., vol. 46, no. 1, pp. 137-167, 2016, doi: 10.1007/s11187-015-9680-y.

[13] G. C. Reid, J. A. Smith, G. C. Reid, and J. A. Smith, "What Makes a New Business Successful ?*," Small Bus. Econ., vol. 14, no. 3, pp. 165-182, 2000.

[14] P. Saxena, "JOHARI WINDOW : An Effective Model for Improving Interpersonal 
Communication and Managerial Effectiveness," SIT J. 134-146, 2015.

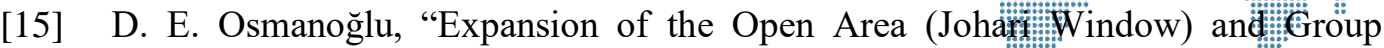
Work Directed to Enhancing the Level of Subjective Wellbbeing," J. Educ. Train. Stud., vol. 7, no. 5, p. 76, 2019, doi: 10.11114/jets.v7i5.4128:

[16] L. Waters, M. Mccabe, D. Kiellerup, S. Kiellerup, S. Journal, and N. Sep, "The Role Of Formal Mentoring On Business Success And Self-Esteem In Participants Of A New Business Start-Up Program The Role Of Formal Mentoring On Business Success And Self-Esteem In Participants Of A New Business Start-Up Program Of Melbourne Kiellerup,” J. Bus. Psychol., vol. 17, no. 1, pp. 107-121, 2012.

[17] J. E. Yusuf, "A tale of two exits: Nascent entrepreneur learning activities and disengagement from start-up," Small Bus. Econ., vol. 39, no. 3, pp. 783-799, 2012, doi: 10.1007/s11187-011-9361-4.

[18] B. Huang, M. Shaban, Q. Song, and Y. Wu, "E-Commerce Development and Entrepreneurship in the People'S Republic of China," no. 827, 2018.

[19] Y. Keat, "A study among university students in business start-ups in Malaysia: motivations and obstacles to become entrepreneurs," Teren. Int. Manag. Bus. J., vol. 3, no. 1, pp. 1-11, 2013.

[20] I. R. Bednár and I. N. Tarišková, "Indicators of startup failure," Int. Sci. J. "Industry 4.0," vol. 5, no. December 2017, pp. 238-240, 2018.

[21] R. Harms and M. Schwery, "Lean Startup: Operationalizing Lean Startup Capability and testing its performance implications," J. Small Bus. Manag., vol. 58, no. 1, pp. 200-223, 2020, doi: 10.1080/00472778.2019.1659677.

[22] R. Chou, "Startups and Investors and Trolls, Oh My!: How Commercialization Patents Can Benefit Startup Innovation," Northwest. J. Technol. Intellect. Prop., vol. 17, no. 3, p. 349, 2020.

[23] judit olah Nicodemus Kitukutha, "Trust And E-Commerce, Case Study On Jumia Company," Econ. Sci., no. 1, pp. 313-323, 2018.

[24] F. H. A. S. Amir Abou Elnaga, "The Impact of E-Commerce on Business Strategy: A Literature Review Approach," J. Am. Sci., vol. 12, no. 5, p. 2016, 2016, doi: 10.7537/marsjas12051608.Keywords.

[25] A. M. M. Al-khattab, "Impact Of Knowledge Management On The Activation Of E-Commerce Using Social Media: Client Approach," Int. J. Econ. Commer. Manag., vol. VI, no. 4, pp. 856-873, 2018.

[26] C. Yung Wei, I. S. Bt Mohd Fauzi, T. R, E. S. Elhag Elhussein, and D. Asirvatham, "E-commerce Adoption and Analysis of the Popular E-commerce Business Sites in Malaysia," Bus. Econ. J., vol. 09, no. 02, 2018, doi: 10.4172/2151-6219.1000347.

[27] A. G. Khan, "Electronic Commerce: A Study on Benefits and Challenges in an Emerging Economy," Type Double Blind Peer Rev. Int. Res. J. Publ. Glob. Journals Inc, vol. 16, no. 1, 2016.

[28] N. Kumar, "E - Commerce in India : An Analysis of Present Status, Challenges and Opportunities," Int. J. Manag. Stud., vol. 2, no. April, pp. 90-95, 2018.

[29] A. S. Alqahtani, R. Goodwin, and D. de Vries, "Cultural factors influencing ecommerce usability in Saudi Arabia," Int. J. Adv. Appl. Sci., vol. 5, no. 6, pp. 110, 2018, doi: 10.21833/ijaas.2018.06.001.

[30] S. F. W. T. Lim, X. Jin, and J. S. Srai, "Consumer-driven e-commerce: A literature review, design framework, and research agenda on last-mile logistics models," Int. J. Phys. Distrib. Logist. Manag., vol. 48, no. 3, pp. 308-332, 2018, doi: 10.1108/IJPDLM-02-2017-0081.

[31] M. S. Kabugumila, S. P. D. Lushakuzi, and J. E. Mtui, "E-Commerce: An Overview of Adoption and Its Effective Implementation," Int. J. Bus. Soc. Sci., 


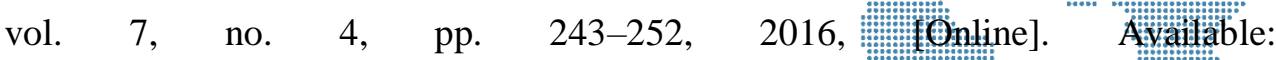
https://ijbssnet.com/journals/Vol_7_No_4_April_2016/27"קet

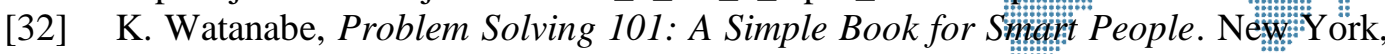
New York, USA: Penguin Group, 2009. 